\title{
Engaging First Year Students Through Crossdisciplinary Design Projects
}

\author{
Emily Marasco, Laleh Behjat, Marjan Eggermont \\ University of Calgary \\ eamarasc@ucalgary.ca, laleh@ucalgary.ca, meggermo@ucalgary.ca
}

\begin{abstract}
As industries increase their preference for hiring engineers with creativity and innovative problemsolving, post-secondary institutions are developing their engineering program to incorporate an increased level of diversity among new students, widening their appeal to students of varied races, gender, talents, and skills.

Studies show that grade school students are most interested in entering fields that involve creative and social aspects, however these are not characteristics that many students associate with engineering. Girls in particular express a preference for careers that involve helping and working with people, and are less interested in science and technology careers due to their perceptions of those fields.

Our research also shows that even students who choose to enter engineering prefer to pursue social and sports-related activities in their spare time, regardless of gender. This paper demonstrates how engineering student hobbies and interests can be used to create engaging, cross-disciplinary projects for teaching first year design principles.
\end{abstract}

Keywords: First-year design, creativity, engagement, diversity, cross-disciplinary.

\section{INTRODUCTION}

Engineering industry leaders, such as Intel and Imperial Oil, are investing resources into the development of diverse, well-rounded future engineers capable of designing innovative technologies and processes [1] [2]. These companies are looking for new employees who exhibit not only the engineering graduate attributes, as outlined by Engineers Canada [3], but who are also capable of creative, independent thought, and the ability to work in multi-disciplinary, and cross-disciplinary, settings.

This research work examines the use of crossdisciplinary design projects for use in a first-year introductory engineering design course to encourage student engagement and interest. These projects were intended to include real world design problems that cross over into other subject areas, such as political/societal issues, artistic design concerns, and creative innovations. The long-term hypothesized outcomes of this work include an increased level of engagement among first year engineering students, leading to a high rate of retention and a higher level of comprehension surrounding engineering design. These outcomes will be tested using both qualitative and quantitative research methods.

This paper examines the preliminary analysis and implementation of cross-disciplinary design projects for engaging first-year students in an introductory design course, and outlines suggested elements for future consideration when designing course projects.

\section{PROJECT DESIGN METHODOLOGY}

\subsection{Introductory Design Course}

At the Schulich School of Engineering, all first-year students are required to take ENGG 200, an exploratory course that introduces students to engineering design principles, teamwork, and creative thinking. In 2013, the course projects were designed around the theme of "No Impact Man", based on the corresponding book studied as part of the university's undergraduate common reading program. The four laboratory projects were developed by interdisciplinary researchers familiar with engineering design and arts concepts, and tested by senior undergraduate students prior to the start of classes. Students were introduced to the engineering design process, and learned techniques for developing a complete design and product. Cross-disciplinary principles were incorporated to encourage engagement from a diverse range of students with varied backgrounds, gender, ethnicities, and interests. Engineering design techniques were combined with fine arts, social issues, mathematics, physics, research, technology and writing to encourage interdisciplinary connections and creative thinking.

\subsection{Project 1 - No Impact Orchestra}

For their first exposure to creative design thinking, students were given three hours to design and construct 
two musical instruments capable of producing identifiable and repeatable frequencies. This project was designed through collaboration with Beakerhead, a Calgary-wide festival for promoting the connections between engineering and the arts. Students were required to create their instruments from materials considered eligible for the City of Calgary's blue bin recycling program, and together the teams made up the Schulich No Impact Orchestra. The project was also developed to include a review of high school technical concepts, including frequency measurements and calculations, and use of basic measurement tools. After completion, student teams demonstrated their projects, and were also given the opportunity to create music videos. Nearly $100 \%$ of the teams were completely successful in achieving the design objectives while being exposed to their first postsecondary teamwork experience.

\subsection{Project 2 - Target on Budget}

The second project introduced students to designing within a budget, where each team was given a finite amount of "money" to spend on their material. The goal of the project was to build a structure capable of delivering a hockey ball from a specified starting height to a target on the floor below. Each structure had to contain a horizontal span of a specified length, as well as a vertical drop or ramp. Students were again limited to common materials that could be recycled, and worked within a three-hour time limit. As with the first project, most teams were successful in completing the task, but with varying degrees of accuracy depending on where their hockey ball landed on the gradated target. This project was also intended to be an introduction to the structural techniques required for the next project.

\subsection{Project 3 - No Impact Bridge}

In the spring of 2013, excessive flooding devastated regions of southern Alberta. The backcountry areas were some of the hardest hit, with many trails and bridges being completely washed away. The third design project was planned in conjunction with Parks Canada and required students to propose a sustainable bridge design that could be assembled in remote areas accessible only by helicopter. Throughout the multi-week project, student teams were required to research, sketch, prototype, and construct their design ideas. Their final designs, made again from recyclable materials, were subjected to both horizontal and vertical load testing based on scaled down measurements of real environmental stressors such as water and wind. Team success varied depending on materials, methods of adhesion, and points of load bearing.

\subsection{Project 4 - Corner to Corner}

The final multi-week project was the only design task that allowed students to use non-recyclable materials, but within a \$20 budget. After being provided with an optional motor, some wheels, and a set of batteries, teams were asked to create a vehicle capable of navigating a large obstacle while moving from one corner of a table to the corner directly diagonal from the starting point. Vehicles were free to bypass the obstacle through a narrow gap on the side, or flip, move, climb, etc. past the obstacle itself. Most teams were able to successfully navigate past the obstacle, and final scores were given based on the vehicle's stopping proximity to the end point.

\section{TESTING AND FEEDBACK}

Following completion of the course, students were asked to provide quantitative and qualitative feedback about the projects, their interests, and their level of engagement in engineering design through an online survey. $45 \%$ of the survey respondents identified themselves as female, and 55\% identified as male.

\subsection{Project Rankings}

Students were asked to rank the projects from their favourite (1) to their least favourite (4). It was interesting to see that female and male students rated their favourite project very differently. 59\% of the male students ranked Project \#4 (vehicle/obstacle) as their favourite project, whereas female students ranked Project \#3 (Parks Canada) as their favourite at $47 \%$. Female students were more split among their ranking of the other three projects, while $50 \%$ of the male students ranked Project \#1 (musical instruments) as their least favourite. These results are shown in Figures 1 and 2.

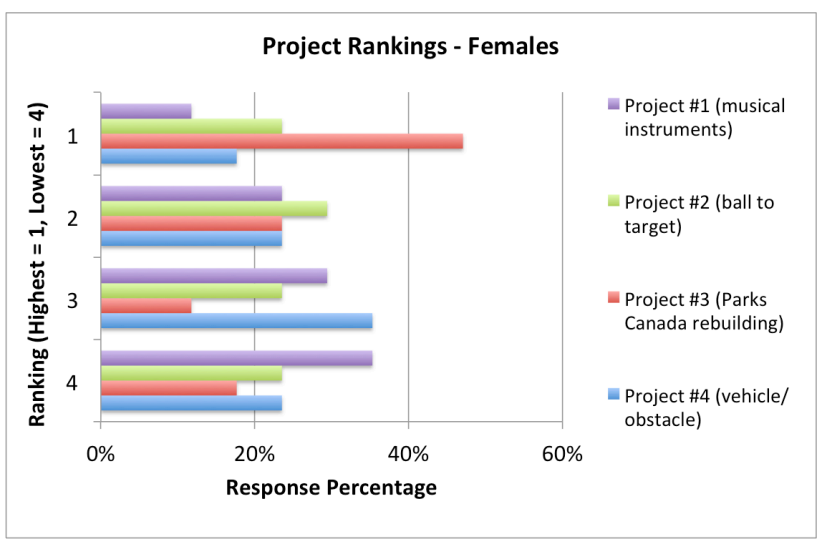

Fig. 1. Female students ranked the project relating to Park Canada rebuilding as their most favourite project. 


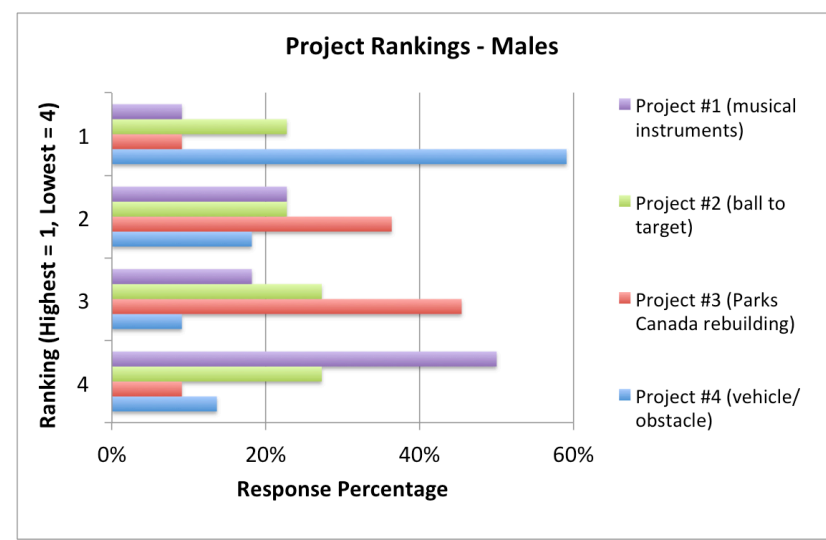

Fig. 2. Male students ranked the vehicle/obstacle project as their most favourite.

\subsection{Student Engagement}

$97 \%$ of all students agreed or strongly agreed that they care more about a project when it relates to their hobbies/interests, seen in Figure 3. However, 72\% of females agreed or strongly agreed that they care more about a project when it has real world applications, in comparison to $62 \%$ of the male students, shown in Figure 4. This is reinforced by the first ranked project of the female students, as the Parks Canada project had the most real world connections and applications.

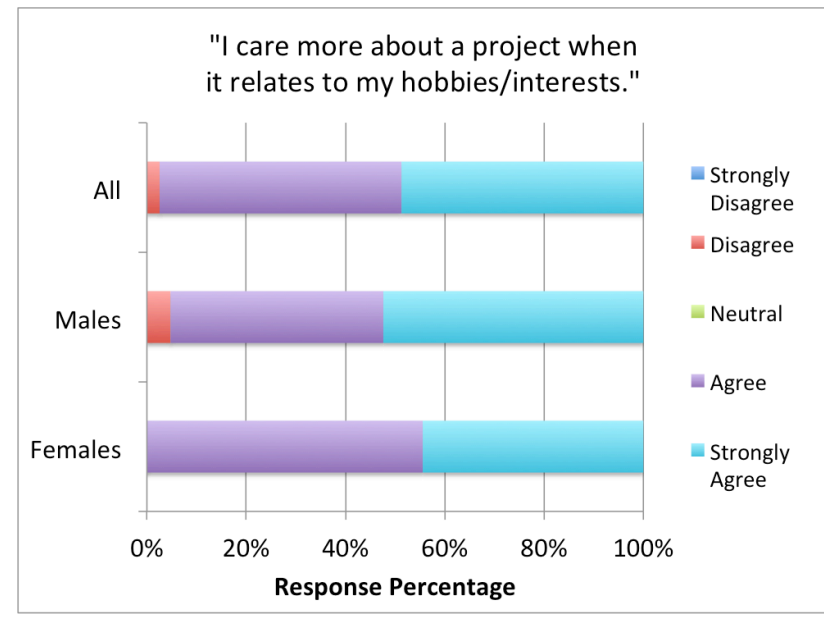

Fig. 3. The majority of students care more about a project when it relates to their hobbies or interests.

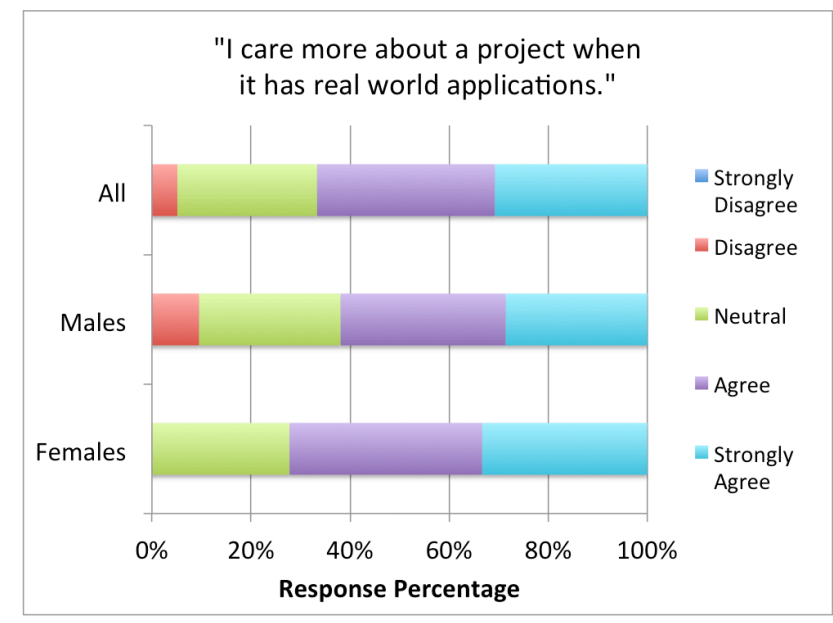

Fig. 4. Female students are more likely to care about a project when it has real world applications.

These percentages are reversed when it comes to challenge in a project. Only $61 \%$ of females agreed or strongly agreed that they care more about a project when it challenges them, as opposed to $72 \%$ of males, as shown in Figure 5. This is also reflected in the favourite project of the male students, Project \#4 (vehicle/obstacle), which presented the most difficult and least constrained design challenge.

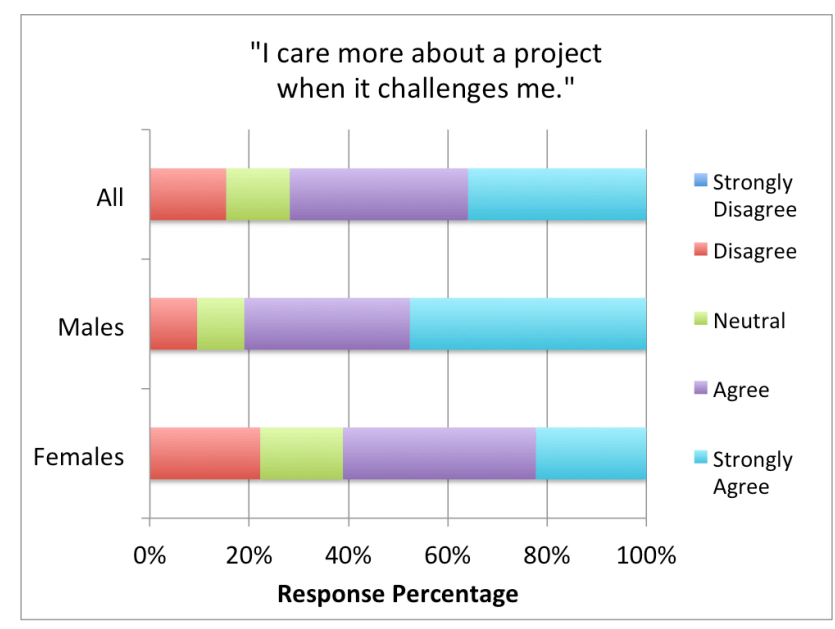

Fig. 5. Male students are more likely to care about a project when it challenges them. 
Figure 6 below shows that male students were also significantly more likely to care about a project when it is very technical, with $90 \%$ agreeing or strongly agreeing in comparison to $39 \%$ of female students.

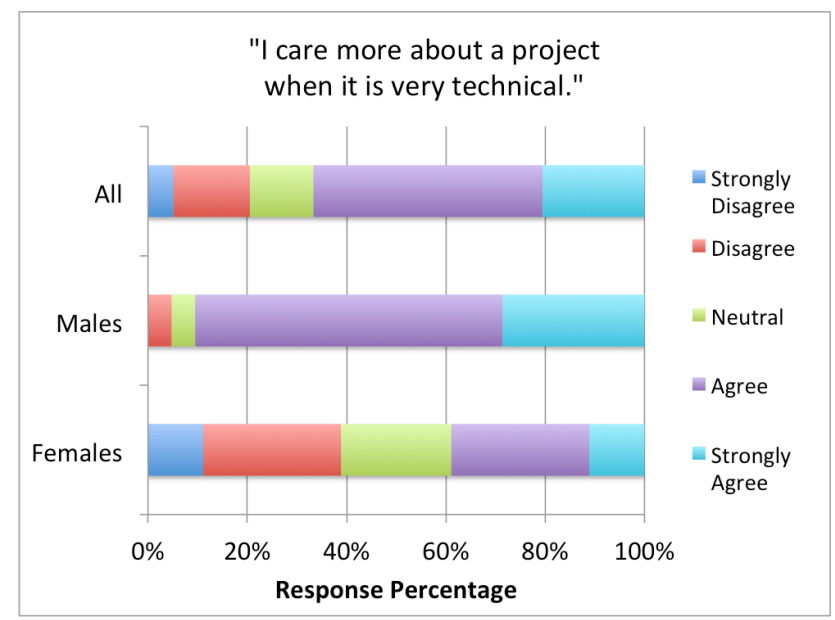

Fig. 6. Male students are more likely to care about a project when it is very technical.

\subsection{Additional Feedback}

Students were given the opportunity to suggest improvements or extensions to the projects presented in their classwork. For the first three projects, students noted that being restricted to recyclable materials presented an additional level of challenge, and they would be interested in repeating the projects without material limitations. Also, students felt that the first two projects were more frustrating due to the time constraints, in comparison to the longer multi-week projects that allowed more time for research and design changes. Students noted that during the later projects they were more comfortable with working in their teams, though some mentioned that their experiences within a project were sometimes tainted by poor team performance or dynamics.

This research study also asked the students to comment on their current interests and hobbies, partially to inform possible future design projects.
Female students identified sports/athletics as their preferred hobby, while male students preferred computer games. Social media and chess/puzzles/board games were also highly ranked by both genders.

\section{CONCLUSIONS}

In conclusion, this paper examines the way male and female students respond to various design projects, and evaluates the factors that increase a student's level of engagement within a project. Female students were found to prefer projects with real world application, while male students feel more engaged in very technical projects. Both genders expressed a high level of engagement in a project when it relates to their own hobbies and interests.

Introducing cross-disciplinary elements and current social issues into engineering design theory can help to implement these factors and create engaging engineering projects that may appeal to both male and female students.

\section{Acknowledgements}

The authors would like to acknowledge the Schulich School of Engineering, Dr. Bill Rosehart, and the ENGG 200 teaching team for their involvement in the design and implementation of the course material. Also thank you to Parks Canada for their involvement and support.

\section{References}

[1] Intel Corporation. (2012). Intel education: inspiring the future. Online:

www.intel.com/content/www/us/en/education/intel-ineducation.html.

[2] University of Calgary Education. (2013). Imperial Oil science technology engineering mathematics education initiative. Online: www.ucalgary.ca/IOSTEM/.

[3] Canadian Engineering Accreditation Board. (2012). Accreditation criteria and procedures. Engineers Canada. 